\title{
ORALIDAD, ESCRITURA Y PRODUCCIÓN DE CONOCIMIENTO: COMUNIDADES DE "PENSAMIENTO ORAL", EL LUGAR DE LOS ETNOEDUCADORES Y LA ETNOEDUCACIÓN
}

\author{
LITERACY, ORALITY AND PRODUCTION OF KNOWLEDGE: "ORAL-THOUGHT" \\ COMMUNITIES, THE PLACE OF ETHNOEDUCATORS AND ETHNO-EDUCATION
}

\author{
Yeison Arcadio Meneses Copete*
}

\begin{abstract}
RESUMEN
En el escrito se presenta una reflexión en torno a la producción de conocimiento en las comunidades étnicas de tradición oral en relación con la escritura y la oralidad, y sus implicaciones para los procesos etno-educativos. En primer lugar, realiza una revisión a la perspectiva occidental en torno a la oralidad y escritura. En segundo lugar, se presenta una conceptualización relacionada con la producción de conocimiento, ésta en relación con las comunidades étnicas de tradición oral, a las que llamaré comunidades de pensamiento oral. Aquí, se reconoce la oralidad y la escritura como formas de producir y ordenar el pensamiento y el conocimiento. En tercer lugar, se aborda críticamente la demanda por la escritura de los maestros etnoeducadores y la demanda de las comunidades afrocolombianas e indígenas por la etnoeducación y el lugar de la oralidad en esta última. Finalmente, se pretende mostrar el encuentro entre la oralidad y la escritura como potencia: complementarios y de soporte para el fortalecimiento y construcción de memoria e identidad en los pueblos.
\end{abstract}

Palabras clave: Oralidad, escritura, producción de conocimiento, etnoeducación, etnoeducadores, comunidades de pensamiento oral.

\begin{abstract}
The current paper presents a reflection about knowledge production in the ethnical communities of oral tradition in relation with orality and literacy, and its implications in the processes of the implementation of ethnoeducation. First of all, it reviews the occidental perspective about literacy and orality. Secondly, it is presented a conceptualization in terms of the knowledge production in relation to ethnical communities traditionally oral, which it will be called, communities of oral thought. In this respect, it is pretended to sustain orality and literacy, from a horizontal viewpoint, as manners to produce and organize knowledge and thinking and not as a vertical over-positioning as occident cultures have imposed. Third, the demanding of teachers' academic writing, and the afrocolombian and indigenous communities historical claiming related to ethno-education,
\end{abstract}

Fecha de recepción: Mayo 15 de 2014 / Fecha de aceptación: Septiembre 12 de 2014

Tipología: Artículo de Reflexión

Para citar este artículo: Meneses, C, Y. (2014). Oralidad, escritura y producción de conocimiento: comunidades de "pensamiento oral", el lugar de los etnoeducadores y la etnoeducación. Praxis. Vol. 10, 119 - 133

*Magister en Educación I.E Enrique Vélez Escobar y Universidad de Antioquia, Colombia, Departamento de Pedagogía, Facultad de Educación. Investigador del Colectivo Ampliado de Estudios Afrodiaspóricos, CADEAFR0. E-mail: yearmeco@gmail.com. 
it is critically approached; as well as the place of orality from the knowledge of popular educators, organizations, ancestors, ancestral authorities. To end up, it is pursued to show the encounter between orality and literacy as potency: complement and support to encourage and build memory and identity within peoples.

Keywords: communities of oral thinking, ethno-educators, Ethnoeducation, knowledge production, orality, literacy.

\section{INTRODUCCIÓN}

"La vocación de la palabra está cifrada en su capacidad para desatar la luz, amansar a los lobos, invocar libertades y hacer del fardo de recuerdos, tradiciones vivas e inmarcesibles" (Ramos, 2006).

L a escritura ha sido superpuesta por el mundo occidental y/o occidentalizado sobre la oralidad; en tanto esta última no tiene un lugar de relevancia en los sistemas académicos y científicos. De manera exagerada algunos autores como Philip Clapham han planteado la tesis de "publicar o perecer", situando la escritura como únicas maneras de ser reconocidos en el mundo académico. La escritura para publicar, particularmente en el contexto universitario, constituye un factor determinante en el ascenso y la visibilización del profesorado. Aunque, es importante manifestar que hay tendencias en las últimas décadas que han desentrañado la relación entre la oralidad y escritura, inicialmente, desde la literatura y la lingüística pasando a otras disciplinas como la antropología, etc.

La oralidad es subalternada al igual que las comunidades que se inscriben en ella o que encuentran una relación histórica estrecha con la oralidad. Comunidades de pensamiento oral: centenares de pueblos en Asia, África, América, Oceanía, etc. En este orden de ideas, cuando se hace referencia a la escritura y la oralidad desde occidente, se plantea en un orden vertical en el cual la escritura posa de superior ante la oralidad. Lo que devela formas históricas como occidente se ha relacionado con los otros pueblos, relaciones de poder-control y dominación. Occidente como el ideal de humanidad, sociedad, progreso y desarrollo evidenciado en el contexto colombiano y en la relación maestro, escritura y producción de conocimiento.

En los últimos años sistemáticamente se ha planteado una demanda más al maestro, la cual vincula procesos como: investigar y publicar, que se concretizan en la imposición del canon de la escritura académica como única forma de producción de conocimiento, en tanto desconoce las múltiples formas a través de las cuales los maestros y maestras desde sus prácticas pedagógicas generan saberes, conocimientos y pasan el lugar de reproductores de los saberes y el conocimiento. De igual manera, se ha instituido la escritura en la escuela con un carácter de obligatoriedad homogenizante que no considera las voluntades, el deseo, la formación y las necesidades de los sujetos (maestros) y los contextos; dado que las condiciones para la escritura son precarias o nulas y la producción de conocimiento no necesariamente debe pasar por la escritura. La escuela y la condición de los maestros y maestras han sido trastocadas por múltiples demandas provenientes de la ciudadanía, los gobiernos de turno y el Estado en el marco de la globalización. Entre las demandas más recientes se encuentra la escritura académica relacionada estrechamente con la demanda por la investigación y la publicación como única forma de producción de conocimiento, por tanto, la única forma para el maestro logran reconocimiento y estatus en la institucionalidad y en la sociedad.

Ante el carácter pluriétnico y multicultural del país surge la etnoeducación como nueva opción pedagógica, la cual pluraliza la categoría maestro. En este marco de ideas, se da lugar a diferentes actores o sujetos como figuras de autoridad y saber en el contexto escolar. Es decir, la etnoeducación reconoce el carácter de maestro no solo a quien recibe en la escuela la licencia 
para formar, sino que por ser una reivindicación fuertemente política vincula chamanes, curanderos, abuelos y abuelas, cantaores y cantaoras y sobre todo líderes y lideresas de las comunidades, todos inscritos mayoritariamente en el pensamiento oral.

Por consiguiente, la demanda por la escritura desconoce y postra comunidades milenarias que han producido conocimientos, forjado memoria e identidad desde el pensamiento oral. Desde esta perspectiva, se aplazan y subalternan las demandas de las comunidades étnicas colombianas por una educación pertinente, acorde con sus cosmovisiones, historias y culturas, lo que se convierte en un atraso para la transformación del sistema educativo colombiano, el cual debe ser pensado en plural. Es decir, responder al carácter pluri-étnico y multicultural de la nacionalidad colombiana. La escritura en relación con la producción de conocimiento es euro-centrada, jerárquica y excluyente.

Sin embargo, aunque la imposición de la escritura por un lado desconozca las comunidades de pensamiento oral, se convierte en una posibilidad de gran importancia para el sustento de la memoria y la identidad de los pueblos afrocolombianos e indígenas, potencia el pensamiento y la construcción de conocimiento y memoria para las comunidades. La escritura y la oralidad han dialogado a través de la historia de la humanidad, por tanto, no puede haber un rompimiento y menos una superposición de una sobre otra. Se propone, entonces, un encuentro entre estas dado que sistemáticamente la grafía ha permeado el pensamiento de las comunidades, lo cual se convierte en una potencia; puesto que se conjugan dos formas de ordenar y producir conocimiento y pensamiento que pueden desarrollar la capacidad creativa e imaginativa de los sujetos y de fortalecimiento de la memoria-identidad.

La relación escritura y oralidad es problemática porque constituyen formas de pensamiento diferenciado, jerárquico y excluyente; por consiguiente pensar la escritura en comunidades de pensamiento oral puede convertirse en una manera de desplazar la cosmovisión de las comunidades y la institución de otro ser de tipo colonial, porque la escritura y la oralidad representan el mundo de manera radicalmente distinta. Aunque en la colonización y los procesos de consolidación de los Estados nación, las comunidades y pueblos de ascendencia africana y aborígenes, son situados en el lugar de la oralidad, pues, los esclavizadores privaron a éstas comunidades de la educación, de sus prácticas culturales, el reconocimiento de su historia, sus deidades y estratégicamente su lengua. La desarticulación de las lenguas, desarticulación de sus mundos, iniciando por someter bajo cadenas a la renuncia del nombre original. De esta manera, la oralidad se convirtió en una estrategia de supervivencia: una forma de poder ser ellos y ellas mismas, recreando su pensamiento, cosmogonía, deidades, prácticas, los recuerdos de la ya lejana África. Se organizaban política y socialmente para resistir y liberarse. La oralidad, entonces, se convirtió en una práctica de libertad.

Finalmente, hoy es necesario encontrar o construir formas o dispositivos alternativos para salvaguardar la memoria-identidad; porque la oralidad-sola, también supone riesgos-posibilidades, en tanto que pude tergiversarse y transformarse, o desaparecer de la memoria-identidad de los pueblos. Aunque la transformación se entiende como una posibilidad porque las identidades no son estáticas y la memoria no es solo pasada, la memoria está también en las recuperaciones del pasado y en las construcciones del presente. Aunque la oralidad ha sido una agencia de resistencia y re-existencia de las comunidades, hoy las imposiciones del capitalismo, neoliberalismo y el desplazamiento forzado amenazan la prevalencia de prácticas ancestrales y cosmogonías.

\section{RESULTADOS Y DISCUSIÓN}

\section{Oralidad, escritura y producción de conocimiento}

La oralidad ha sido subalternada por la cultura occidental. Es así como en el campo de lo científico y literario de la lengua y la literatura ha sido evitada. En este sentido, parafraseando a Ruth Finnegan (citado en Ong, 2006) las artes, 
las ciencias humanas y sociales, durante siglos basaron sus tesis en textos escritos y consideraron la oralidad como variantes (secundarias) de las producciones escritas; o bien indignas del estudio especializado serio (p. 18). En tanto hasta nuestros días la oralidad sigue siendo marginalizada. Así mismo, el profesor Zapata (2010) plantea que:

La sacralización de la escritura que ha tenido por contraparte un menosprecio por la oralidad, lo que además ha significado para esta última la inaccesibilidad al plano de lo estético. Por esto mismo, desde que con las teorías literarias del siglo XX se propuso una ciencia del texto literario escrito, la oralidad, en razón de su misma fugacidad -lo que la hacía de alguna manera inmanipulable-, pareció no ofrecer atractivo alguno para los estudiosos de la literatura; a lo que se suma la negativa y a veces despectiva asociación de la oralidad con lo primitivo y lo tradicional, en virtud de lo cual una sociedad en transformación presta toda su atención a aquellos aspectos que determinan su evolución y se desinteresa o arremete contra todo lo que se identifique con su estado anterior (p. 143).

La oralidad aunque aparece como una obviedad su relación interdependiente en relación con la escritura, no tiene un lugar de dignidad en la historiografía, en el mundo de la academia, la ciencia, la investigación, la intelectualidad y el pensamiento. Como lo señala Balerstrini \& Chicote (1997):

Decir que el lenguaje es un fenómeno esencialmente oral parece una obviedad. Sin embargo, el análisis científico y literario de la lengua ha evitado, hasta hace muy poco tiempo, atender este aspecto. Los estudios se concentraron en los textos escritos por una razón comprensible: la relación del estudio mismo con la escritura que extiende la potencialidad del lenguaje ilimitadamente (p. 43-44).

“Todos los textos escritos tienen que estar relacionados de alguna manera, directa o indirectamente, con el mundo del sonido, el ambiente natural del lenguaje, para transmitir significados" [...] "La escritura no puede prescindir nunca de la oralidad" (Ong, 2006, p. 17). Asimismo, los textos orales tienen representaciones gráficas y simbólicas convencionalizadas. La escritura y la oralidad guardan una relación de interdependencia en la medida en que la oralidad y la escritura se dan lugar y soporte recíprocamente. En términos de procesos de pensamiento en relación con la oralidad, el lenguaje, sonido articulado y su importancia, sustenta que la importancia de éste no se centraba en la comunicación, sino en el pensamiento mismo, se relaciona de un modo enteramente propio con el sonido" (Ong, 2006).

La escritura un sistema secundario de modelado, que depende de un sistema primario anterior: la lengua hablada. La expresión oral es capaz de existir y casi siempre ha existido, sin ninguna escritura en absoluto, empero nunca ha habido escritura sin oralidad (Ong, 2006, p. 18). En este orden de ideas, Portelli (1991), (citado en Caicedo 2008) propone que no hay que creer que lo oral y lo escrito son mundos separados, pues el testimonio es básicamente oral aunque esté escrito (p. 29). En este orden de ideas, la oralidad constituye para algunos pueblos milenarios,

Uno de los tesoros más valiosos y abrazados por la tradición de los pueblos africanos es, sin duda alguna, la expresión oral. La palabra que asombra, la palabra que sentencia, la palabra que crea y que se canta, gran práctica ancestral y fuertemente arraigada en el espíritu de estos pueblos, se fue construyendo y consolidando con el tiempo no sólo como una fuente inagotable de conocimientos y experiencias, sino también como parte fundamental de su vida, de su cotidianidad, de su propia esencia (Munguía, 2010, p. 2).

El tránsito de la oralidad a la escritura reconfigura y transforma la relación comunidad de pensamiento oral-representación simbólica y de significación. Una persona que ha aprendido a leer no puede recuperar plenamente el sentido de lo que la palabra significa para la gente que sólo se comunica de manera oral” (Ong, 2006, p. 
20); lo cual sugiere que la oralidad y la escritura obedecen a una lógica diferenciada que se mueven por la esencia de la significación, el tiempo y lugar de la palabra. De hecho, una de las decisiones más difíciles a las que se enfrenta un escritor es precisamente elegir la palabra "correcta" para decir lo que se quiere decir. Además, que no se puede hablar un sometimiento a la escritura que desplace la potencia del pensamiento oral.

Los códigos, la grafía es una representación del pensamiento y el cuerpo humano; puesto que la escritura expone en gran manera experiencias sociales-culturales que han pasado por el cuerpo y que han sido puestas en un lugar del pensamiento. En este sentido, "la escritura es saber no solamente porque se sepa escribir, sino ante todo porque se conectan cerebro y mano en una acción cognitivo-lingüística que comporta implicaciones en los órdenes del pensar, del hacer y del ser dentro de la cultura" (Echeverri, 2011, p. 32).

Existen lógicas de poder y saber, en la escritura, empleadas en la construcción de la alteridad, la construcción de otro; también, los "monopolies of knowledge"1. La escritura ha jugado un papel determinante en la construcción de la historia de los pueblos, que no han obedecido a lógicas inocentes. A través de ésta se ha configurado sociedades y sistemas de representación sobre poblaciones. Sin embargo, ha sido fundamental en el reconocimiento del pensamiento de siglos pasados que han sido base fundamental para la transformación del pensamiento de las personas en el presente y proyectados hacia el futuro de la humanidad misma.

La escritura tiene una estrecha relación con el establecimiento de un orden social, confiere poder y ofrece posibilidades (Vásquez, 2008). El gran ensayista y crítico latinoamericano, Ángel Rama, en el texto La Ciudad Letrada, muestra de manera ilustrativa el lugar (peligro, utilidad) de los signos, la grafía, el lenguaje en la construcción de las ciudades particularmente. Los ilustrados en el

1. Para Harold Innis, la alfabetización impulsa "monopolios de conocimiento" que permitidos por el desarrollo de imperios militares y también funcionaron en oposición a la tradición oral (Innis, 1986:5 en Mason, 1998). siglo XVI escribían desde el lugar de enunciación del colonizador, dominante, superior. Entonces, hay un vínculo estrecho entre la escritura o la grafía y las relaciones de poder que se construyen o reproducen en un contexto social.

En este contexto histórico la grafía, la escritura, jugó un rol central en la construcción e imposición de un orden simbólico social-jerárquico de la ciudad, las ciudades imaginadas o sociedades imaginadas. Por consiguiente, el orden simbólico y la posterior materialización de la ciudad excluían la representación y el mundo simbólico de los colonizados y/o sub-alternizados; los cuales fueron representados e "historizados" por la pluma de la dominación. Los blancos, negros, indios son construcción social del mundo moderno-colonial; estructuras de poder moderno soportado por la gran “imaginación” de la escritura-colonial. En este orden, la pluma convirtió un mundo imaginario de sujetos civilizados y el universo de los salvajes.

Desde otro punto de vista, "las relaciones entre oralidad y escritura, amplios, incluso, vastos conocimientos, pensamiento concienzudo y formulación cuidadosa, no solo son profundas y complejas las cuestiones; sino que también comprometen nuestros propios prejuicios" (Ong, 2006, p. 12). La oralidad es potenciada por la escritura; en palabras de Ong (2006):

La escritura no redujo la oralidad sino que la intensificó, posibilitando la organización de los "principios" o componentes de la oratoria en un "arte" científico, u cuerpo de explicación ordenado en forma consecutiva que mostraba cómo y por qué la oratoria lograba y podía ser dirigida a obtener sus diversos efectos específicos (p. 19).

La sociedad del conocimiento y de la ciencia, los avances tecnológicos y la globalización han generado grandes tensiones y demandas en los últimos tiempos en el sentido de la producción de conocimiento; es decir, investigar, escribir y publicar. Todas esta tienen una gran fuerza en la Universidad y caminan hacia la secundaria y la primaria, por supuesto demarca exigencias e imposiciones a las tareas de las y los maestros. 
Además, la perspectiva de la producción de conocimiento no tiene fundamentos epistémicos contextualizados y desplaza a etnoeducadores, los nuevos sujetos de la educación colombiana.

\section{Colonialidad y producción de conocimiento}

En el encuentro entre los mundos: indoamericano, africano y europeo, tomó fuerza la idea de un conocimiento, una historia universal. Por supuesto, desde las lógicas capitalistas, colonizadoras, se situó en occidente, con fuertes argumentos racistas. Aquí, en el contexto de la producción de conocimiento quedan out tanto África como Latinoamérica. El conocimiento era únicamente posible en el mundo europero-blanco. Algunos pensadores reconocidos contribuyeron en la reproducción de esta ideología.

Un ejemplo de esto se encuentra en el pensamiento del reconocido filósofo Immanuel Kant. Kant Argumentó en los siglos XVIII y XIX que la única "raza” capaz de progreso en las artes y las ciencias era la "blanca" europea. Al establecer un cuadro jerárquico basado en la relación entre naturaleza humana, conocimiento y color de la piel, de superior a inferior, localizando los "rojos" y “negros” en los peldaños más bajos, Kant dio al conocimiento tanto un lugar como un color: el blanco (Walsh, 2004a, p. 34).

La producción de conocimiento resulta también problemática. Ésta ha sido ligada al mundo occidental y occidentalizado y particularmente a la escritura, encontrando como claustro la universidad, institución que ocupa un lugar de autoridad y poder-saber, con el saber producto de la investigación, un saber "objetivo", que hacen parte de la alfabetización de las sociedades convirtiendo en sentido común sus elaboraciones, pero este claustro también toma y hace suyos el lenguaje de la sociedad. La escuela sigue siendo marcada por la enseñanza de la lectura y la escritura. La alfabetización, en este contexto, deviene en la escritura propiamente, pero también es problemática en términos de la imposición de la escritura y supra-valoración sobre las apuestas discursivas orales del profesorado y estudiantado en las universidades y en la escuela, la divulgación, circulación o el dilema de la publicación, una demanda controladora y hegemónica de la producción del conocimiento, en tanto sepulta, trivializa y reprime otras formas de crear, construir y difundir los conocimientos nuevos. "La escritura académica es una alfabetización que implica dominio de un tipo de lengua escrita legítima: sus formas, sus prácticas, sus recursos expresivos, rebuscados y elocuentes, su función directamente ligada a la producción y legitimación del conocimiento académico" (Hernández, 2009, p. 13).

Sin embargo, la producción de conocimiento y el pensamiento complejo no están sólo en la escritura. En este orden de ideas la escritura es una forma o un dispositivo de la ciencia en el mundo moderno; que entre otras cosas cada día "reconoce la pluralidad y la diversidad", lo cual muestra una contradicción en el ámbito Universitario o escolar, la demanda por la escritura y el reconocimiento de la diversidad étnica y cultural del país. Éste último supone el reconocimiento de esas otras formas de ser, estar, saber, conocer en el mundo. La oralidad, por supuesto, debe ser acogida, en el marco de tal "reconocimiento" por el sistema educativo, la escuela y la Universidad sin "folklorizar y exotizar", dada la relevancia que ésta ha tenido para los pueblos de ascendencia africana en las Américas como símbolo de resistencia, re-existencia, libertad, identidad y de poder creativo-imaginativo.

Pero, en términos de producción de saber y conocimiento para el caso de las comunidades o pueblos afrodescendientes, no están relegadas o son despreciadas en la academia solo a razón de su lugar como pensamiento oral, también desde los cánones de la escritura misma. En el mundo de la grafía, las contribuciones afros al conocimiento universal son relegadas y malcontadas, y no hacen parte de los discursos institucionales en las escuelas y universidades: son declarados faltos de validez, profundidad, seriedad, sentimentalistas, etc. a Anthony Borges (citado en Walsh, 2004) en dialogo con el filósofo jamaiquino Lewis Gordon, muestra cómo se subalterna y se menosprecia el conocimiento de autores afros alfabetizados: 
El problema descansa en que el pensamiento de los intelectuales afros es únicamente considerado como derivado de la "experiencia" negra de la esclavitud, el colonialismo, el racismo y otros fenómenos sociales y por esta razón, desprovisto de un pensamiento serio, original y global [...] En este marco, las ideas de pensadores como Fanón y Du Bois no son consideradas como intelectualmente originales o independientes; existen solo en relación con y como resultado de un sistema de pensamiento ya aceptado como "universal"; un sistema que tiene un lugar de origen y un color: la razón blanca de occidente. De hecho, la historia del conocimiento está marcada geo-históricamente, geo-políticamente y geo-culturalmente y, por eso, tiene una relación y forma parte integral de la construcción y organización del "sistema mundo moderno (Walsh, 2004a, p. 333).

Por otra parte, Deborah Tannen (citada en Mason, 1998) sustenta que la oralidad y la escritura no pueden ser vistas como "estrategias" opuestas y por separadas. Lo cual hace del encuentro entre estas, una posibilidad para la producción de conocimiento. Los autores muestran una relación de continuidad entre oralidad y escritura.

She (Deborah Tannen) proposes that we should replace the oral-literate divide with a continuum and states that "both oral and literate strategies can be seen in spoken discourse. Understanding this, let us not think of orality and literacy as an absolute split, and let us not fall into the trap of thinking of literacy, or written discourse, as decontextualized" (Mason, 1998, p. 312).

La producción de conocimiento la encontramos tanto en la escritura como en el pensamiento oral. La escritura y la oralidad son técnicas o estrategias independientes a la producción de conocimiento, en tanto que no toda escritura, no toda manifestación de pensamiento oral es per se producción de conocimiento. La producción de conocimiento obedece a procesos complejos de sistematización de formas de aprensión del mundo o de la "realidad". Y la complejidad, el orden y la sistematización no están en las grafías solamente; la oralidad tiene sus formas de organización y ordenamiento del conocimiento. Aunque es válido preguntarnos: ¿la oralidad puede ser sistemática, ordenada en términos de la producción de conocimiento? En el caso de las comunidades africanas y afro-diaspóricas la oralidad fue más allá de un lenguaje articulado.

La característica más palmaria del africano es y ha sido el lenguaje oral, pero la oralidad no ha sido simplemente un símbolo mental que figura algo, sino el equivalente a una memoria, a una tradición, a una cultura específica. La oralidad, la invención de una lengua es, de cierta manera, una forma de salir del mundo natural para advenir al de la cultura humana, social e histórica [...] no deja de resultar asombroso que el Muntú afro en América, aprovechando el poder del imaginario creador colectivo, haya inventado "nuevas" formas, palabras, lenguajes, para designar con nombres africanos esta geografía extraña para ellos, pues, bajo el yugo de la explotación esclavista, colonial, perderán sus lenguas nativas. La invención del palenquero como lengua franca es el intento de buscar un punto de convergencia para buscar la libertad y afirmar la identidad; sin comunicación común hubiese resultado casi imposible unificar el proyecto del fin de la servidumbre aquí en América (Mina, 2006, p. 71).

Si consideramos la producción de conocimiento como proceso sistemático y ordenado, encontramos desarrollos científicos y académicos de los últimos años que permiten plantear que la oralidad resulta ser sistemática y ordenada. En este sentido, el método analítico sustenta cuatro procesos para investigar; entonces "producir conocimiento" en la modernidad: entender, criticar contrastar e incorporar. Entender, consiste en estudiar la lógica interna del texto (discurso), es decir, su coherencia lógica, "las reglas de formación y los postulados explícitos e implícitos que fundamentan el discurso, así como los métodos de demostración y sustitución de imágenes, conceptos y enunciados, 
y las reglas de interpretación de símbolos". Criticar hace referencia a "establecer una comparación del texto consigo mismo y con otros del mismo autor o de distintos autores". Contrastar re relaciona con el "recurrir a la experiencia, a la práctica social, experimental o existencial. Verificar en la praxis la validez y las consecuencias del discurso: su eficacia y fecundidad". Finalmente, incorporar el cual consiste en "lograr que el texto sea asimilado, en primer lugar, por la teoría personal, y luego, por el propio cuerpo; convirtiéndose en parte de la actitud, del modo de ser: en un saber incorporado" (Ramírez, 2000; citado en Lopera, et al, 2007, p. 25-26).

Desde la experiencia profesional y personal como etno-educador-activista afrodescendiente en un sistema educativo que no alberga propiamente la diversidad etnica y cultural en sus discursos, he incorporado el método analítico. Aunque no he recurrido a la publicación de los trabajos de contrastación, crítica, comprensión e incorporación, frecuentemente enfrento de manera crítica y dialógica, desde la perspectiva etnica afro y de equidad de género, los discursos de los textos escolares que leen y las reacciones socio-críticas de las y los estudiantes. Tarea que un gran número de profesores, maestros y maestras asumimos de cara a las transformaciones políticas, sociales, culturales y económicas del país. Además, si consideramos las comunidades de pensamiento oral, "las practicas de produccion y socialización de ideas y conocimientos no pasan necesariamente por la escritura. Esto es, que dicho ejercicio puedecorresponder exclusivamente a la oralidad $\mathrm{u}$ otras formas de lenguaje, asumiendo queen los regímenes intelectuales un código no niega el otro, y por el contrario en la gestión de este tipo de proyectos tienden a ser complementarios (Arboleda, 2011, p. 6).

La escuela en sus procesos de enseñanza y aprendizaje alberga la produccion de conocimiento que no esta mediada totalmente con la escritura, en contraste, estos procesos se centran en gran medida por la oralidad. En el contexto escolar el maestro es reducido a la "escritura notarial", la cual sustenta la marcación de la oralidad en la escuela. En la profesión docente, en la formación basica y media, los docentes enfrentan multiples complejidades sociales que reposan en la escuela y encuentran en ella una posible salida al entramado social: desigualdades sociales, violacion de derechos humanos, derechos laborales, pobrezas sistemáticas e históricas, el capitalismo desenfrenado, sexismo, racismo, etc.

En este orden de ideas, el contexto escolar se convierte en una alternativa para la transformacion del orden social establecido. Esta realidad agudiza la "culpabilización" de la escuela y la labor de los maestros y maestras. Tambien limita, no la producción de conocimiento; pero si la escritura según los cánones académicos. ¿en que momento escriben las y los maestros? ¿Cuándo investigan y sistematizan (escriben) sus experiencias? Sin embargo, es valido anotar que pese a toda la responsabilidad social que recae sobre las y los maestros, hay experiencias marcadas de docentes que se arriesgan y se empoderan de la tecnica de la escritura, y en la logica actual, producen conocimiento.

En este orden de ideas, maestros y maestras, en las múltiples actividades y carreras de la escuela, producen saberes y conocimientos basadas en la cultura de la oralidad que no, necesariamente, pasan por la escritura para que las y los sujetos entiendan, critiquen, contrasten e incorporen. Maestros y maestras una vez reciben la licencia para enseñar, vivencian el método analítico o sus procesos mejor, a través de los cuales configuran su identidad y se profesionalizan desde la experiencia de su quehacer pedagógico. 
Tomando en consideración el pensamiento de Paul Ricoer cuando dice: "el maestro cuando enseña habla"; se puede colegir que la identidad de la escuela está marcada por el pensamiento oral de maestros y maestras, su momento, su tono, ritmo, su lugar y sus razones. En lo que no está escrito. No en el texto guía sino en los textos orales que tienen lugar en la relación maestro (a)- estudiante, estudiante-maestro (a) y cómo éstos entretejen sus subjetividades. En este sentido, los cuestionamientos al texto guía, los discursos críticos, el zigzagueo y los repensares del maestro crítico, hacen parte de la producción de conocimiento.

La escuela tiene sentido e identidad por el habla, la intención, los sonidos y las voces que en su interior se expresan. Por esta razón, la memoria y la identidad de la escuela se forman, preponderantemente, en la palabra, en la oralidad, lo que efectivamente no está escrito. Además, la relación conflictiva entre maestros-directivos docentes, maestros-políticas de los gobiernos frente a la educación, la apuestas del sindicalismo del magisterio, soportan el lugar de agente de transformación social, un intelectual. Aunque, es necesario precisar que no todos se inscriben en este lugar de enunciación y que es posible transformar desde otros lugares. Pero, es también valida la pregunta por la difusión y el compartir de pensamiento sustentado en la oralidad. La publicación o difusión del pensamiento oral es mucho más lenta, puesto que tiene "menor valor" en lo académico, por ejemplo; sin embargo, ésta se mueve, viaja y adquiere un cuerpo en la escuela, la cotidianidad y en la vida social.

Empero, la escritura es, también, en la actualidad una posibilidad y una potencia para las comunidades de pensamiento oral y maestros y maestras, en términos del posicionamiento o del regreso de la voz de éstos sujetos sobre la escuela y los saberes que en ésta se difunden. La escritura sitúa al docente como productor de conocimiento y no un simple agente que reproduce los discursos que otros construyen para la escuela y sujetos escolares de determinado orden social. "Debemos lograr que nuestro pensamiento y nuestras ideas sean "otro texto" entre los que circulan y llegan a nuestros alumnos. Hay que ir a clase con esos útiles hechos por nosotros mismos, hay que atreverse a hacer público nuestro pensamiento, hay que sumar-a la herencia cultural que nos ha tocado en suerteuna reflexión vuelta texto de trabajo, una tesis convertida en un ensayo, una pregunta hecha proyecto de investigación” (Vásquez, 2008).

En este sentido, se trata de poner en diálogo la oralidad y la escritura de manera horizontal; se podría decir, parafraseando al profesor Echeverri (2005) "la escritura que da fijeza a la oralidad construyen un tipo de memoria específica", sumaría, la oralidad da fijeza a la escritura puesto que se escribe para ser leído y se lee para escribir. La relación oralidad-escritura es irrompible. Es en la oralidad donde lo escrito adquiere cuerpo y viaja en el pensamiento humano, instala y reconfigura la memoria identitarios de los pueblos. El binomio oralidad-escritura como formas diferenciadas potencias las luchas por la identidad y la memoria colectiva de la diversidad constitutiva de la colombianidad.

\section{Etnoeducación, oralidad y escritura}

La memoria no es un objeto claramente identificable sino, más bien, el resultado de una práctica que es siempre performativa y que, en nuestro caso (Vich y Zavala), tiene en el discurso oral una de sus posibilidades de actualización. Se trata de un reservorio de contenidos latentes que recién se manifiestan a través de su performance (Lienhard, citado en Vich y Zavala, 2004, p. 18).

El lugar de la oralidad no sólo obedece a las formas de desarrollo civilizatorio adoptado por un pueblo, sino también a lógicas y a momentos históricos que la originan. Algunas culturas son situadas en el lugar de la oralidad a razón de estructuras de poder, de dominación, esclavización, explotación y de racialización. Esto no quiere decir que la oralidad sea un lugar 
subalterno per se, sino que en momentos históricos resultó ser el único dispositivo para la reconstrucción, liberación y revolución desde un universo propio. En la actualidad, algunas comunidades guardan una cercanía con el pensamiento oral, porque históricamente fueron situadas en este lugar (muchas de las culturas americanas y africanas históricamente no han sido ágrafas, la cultura Egipcia en África antigua y los mayas en las Américas); como forma de invalidar su humanidad, reducir, sus conocimientos y el pensamiento. La negación de la educación y con ello el conocimiento de la grafía, impusieron, en el algunos casos y fortalecieron la cultura de la oralidad en las comunidades milenarias.

Asimismo, ante los procesos reduccionistas de la historia de las comunidades afrodescendientes e indígenas en la historiografía nacional oficialmente escrita, la resistencia desde el pensamiento oral cobra gran relevancia para la pervivencia de la memoria e identidad de éstos pueblos. "Muchos discursos orales son formas de memoria colectiva a traves de las cuales los sujetos encuentran fundamentos para construir su identidad y repensar su presente" (Vich \& Zavala, 2004, p. 18). En este sentido, el profesor de la Universidad del Cauca, José Antonio Caicedo sustenta que:

Teniendo en cuenta el mecanismo de invisibilidad/ invisibilización histórica al que han sido sometidos los afrocolombianos en el espacio gramatical de la historia escrita, los relatos orales constituyen recursos valiosos para indagar otros registros del pasado afrocolombiano, acudiendo a los resquicios de la memoria de individuos o grupos, con lo cual se presenta una alternativa para recabar la historia cercana de localidades donde se asienta población negra, más allá de la evidencia escrita (Caicedo, 2008, p. 29).

La oralidad guarda ventajas y desventajas en dos sentidos: en primer lugar, se da una transformación en el sentido "puro" de la palabra, el sonido y los gestos. La palabra puede ser discutida, compartida e interrumpida, ella viaja con el pensamiento. La oralidad también devela relaciones de poder vertical, en las comunidades de pensamiento oral. Quien habla, generalmente, ocupa un lugar de autoridad, de poder en el contexto social, político, cultural y económico. La voz del taita y la curandera, por ejemplo, son lugares y voces de privilegio en las relaciones y prácticas sociales de las comunidades; hasta en las formas de transmisión de éste saber. Ésta última, también atravesada por un ética-misterio-espiritual y relaciones de poder. Entregar este saber, es entregar un poder, la espiritualidad del pueblo y la vida; aunque el hecho de que algunos y algunas sabedores afros e indígenas hayan llevado a la tumba estos conocimientos, vigentes para una mejor vida o un etno-desarrollo, debe ser materia de revisión profunda, detenida y compleja en estos pueblos. Adicional a lo anterior, el universo de la oralidad y la jerarquización representan un peligro para el sustento de la memoria y la identidad colectiva de los pueblos; lo cual pone sobre el tapete la posibilidad de integrar la escritura. "En estos momentos de la postmodernidad aparece la necesidad urgente de escriturar y graficar nuestras formas de pensamiento, de acción y de desarrollo que se han ido perdiendo especialmente por la urbanización paulatina y el desplazamiento forzoso de los campesinos de pacifico a la ciudad" (Suarez, 2010, p. 2518).

De manera que con el tiempo la palabra oral, los saberes, los eventos, prácticas pierden significación y desaparece en sí como palabra hablada en su esencia; lo cual dificulta la configuración particularidad de la cultura, pensamientos, sentimientos y formas de representar el mundo. Pero la palabra, el gesto y toda forma de expresión tienen un tiempo y un lugar sea en formato oral o escrito. Entonces, esta reconfiguración o nueva forma que recibe la palabra en la cultura oral puede ser simplemente una perdida irrecuperable del pensamiento oral en estas 
culturas. En la retórica, “una vez tenían lugar las alocuciones, después de pronunciar el discurso, no quedaba nada de él para el análisis. Así, los discursos estudiados eran los escritos, por tanto la memoria que se construye da un lugar privilegiado a lo escrito” (Ong, 2006, p. 19). Por consiguiente, la oralidad y la producción de conocimiento desde ésta pierden valor social y validez en el ámbito de las ciencias. Para el caso de las comunidades milenarias, el lugar privilegiado de la escritura para efectos de estudios y de reconstrucción epistemológicas, jugó y juega un rol determinante en la perdida de algunas prácticas, saberes, producción de conocimiento y pensamiento ancestral. Es aquí donde se fundamenta la demanda por encontrar lugar para culturas orales opuestas y divergentes a la occidental, a partir de políticas, acciones, programas, etc; además impulsar el encuentro oralidad y escritura que eleven el quehacer pedagógico de los etnoeducadores, los nuevos sujetos de la educación. "Para el caso de la etnoeducación afrocolombiana, no nos queda más salida que mejorar los procesos, estrategias y mecanismos de la oralidad y adentrarnos a la alfabetización gráfica-textual en procesos de comprensión y producción que permitan mantener el pasado vivo y dejar por escrito de manera clara y explícita la novedad de la letra como otra opción para mantener la cultura afro-pacífica y permitir que ésta entre y salga de la escuela”. (Suarez, 2010, p. 2518). Aunque la salida no está en desplazar la oralidad o trasladarnos a la escritura sino en democratizar y multiplicar los formatos, desde los procesos etnoeducativos, las formas como circulan los saberes, la historia y las prácticas en la palabra.

Por otra parte, el pensamiento de grandes líderes y lideresas afrocolombianas que marcan la ruta en las luchas históricas y reivindicatorias de la etnicidad, quizás no hubiera sido posible su visibilización y difusión en las nuevas generaciones sino a través de la escritura. Pero, ésta no puede ser un canon inflexible en el ámbito académico. Se entiende la relación entre escritura y oralidad como el encuentro entre dos formas de producción de pensamiento diferenciadas que configuran un binomio que potencia el pensamiento. Heath (1982) (citado en Hernández, 2009) muestra esta relación: "los eventos de habla pueden describir, repetir, reforzar, expandir, enmarcar, o contradecir los materiales escritos, y los participantes deben aprender si el modo oral o escrito tiene predominio en un evento de escritura” (p. 20). La esencia del lenguaje y la palabra en sí, formando un grado o campo profundo de significación y representación.

La sub-alternización de la oralidad en el ámbito escolar guarda una relación conflictiva con la apuesta o reivindicaciones históricas de las comunidades afrodescendientes e indígenas por la etnoeducación; puesto que ésta última pluraliza la categoría Maestro, dando lugar de decoro en la escuela, a las organizaciones, ancestros mayores, autoridades comunitarias, médicos tradicionales, curanderos, parteras, etc; los cuales permanecen cercanos a la oralidad y hasta el analfabetismo. Así, se evidencia la permanencia de lo que Boaventura de Sousa Santos ha llamado Monocultura del saber. "Es decir, la ignorancia presente en la noción moderna/colonial de una sola cultura de conocimiento, que lleva a desperdiciar la experiencia social de otros seres y sus conocimientos. Una manera de confrontar o desafiar esta monocultura podría ser a través de la noción de lo que yo he llamado la "interculturalidad epistémica”" (Walsh, 2004, p. 338). En la escritura académica y en la demanda actual por la misma, permanecen los cánones modernocoloniales en relación con el conocimiento. En este sentido, es válido preguntar: ¿Qué ha representado o que representa la diversidad étnica y cultural para los cánones de la academia en materia de producción de conocimiento?

El lugar que ocupa la escritura en el contexto escolar sustenta imaginarios y prácticas

2. Una práctica política y como contra-respuesta a la hegemonía geopolítica del conocimiento; como una forma "otra" de pensamiento desde la diferencia colonial, necesaria para la construcción de un mundo más justo (Walsh, 2004b, p. 3). 
sociales, las cuales evidencia "que la valoración (de la oralidad) queda reducida al reconocimiento de cultura típica o de folclor vistoso, que no deja de ser subvaloración de la oralidad” (Echeverri, 2005, p. 96). Las formas de organización y producción de pensamiento de comunidades de pensamiento oral: indígenas, rom y Afrodescendientes, desde los cánones de la escritura, son reducidas a culturas primitivas, pre-lógicos e ilógicos. Se da un espaldarazo a las políticas educativas nacionales que "reconocen" las diferencias culturales y étnicas, y sustentan la obligatoriedad de incorporarlo en la formación de las y los colombianos. Tal reconocimiento debe motivar la valoración en los procesos curriculares y en la cotidianidad como ejes fundamentales del proceso formativo, una posibilidad para la escuela leerse desde otros lenguajes y hacer de la diversidad lingüística, la oralidad particularmente, una potencia en la enseñanza de las ciencias en la escuela.

De otro lado, es necesario aclarar que el encuentro entre oralidad y escritura en los procesos de formación y en el ejercicio profesional del profesorado no proponen convertirse en un mandato a secas, sino un contexto de posibilidad y de potencia en los procesos de enseñanza y aprendizaje. En este sentido, el ejercicio de la escritura de maestros no se piensa desde una "rigidez intelectual", menos desde una diferenciación entre el pensar y el hacer; en el sentido en que no es la escritura necesariamente la que da lugar y dinamiza el carácter creativo, emancipativo e intelectual del maestro u otorgue un lugar de superioridad ante la oralidad y las otras formas como éste configura el pensamiento; ese lugar de no palabras, por ejemplo. La escritura del maestro se presenta como una potencia que, como se ha manifestado previamente, permite a este actor de la educación elevar, abstraer, alejar, encontrar, desnudar y transformar su pensamiento, discurso y acción, por tanto volver sobre el lugar del maestro y la relación con sus estudiantes, la academia, los saberes, las culturas y la sociedad en general. Por tanto, la escritura en vínculo con la oralidad da lugar a formar otra subjetividad e intersubjetividad en el maestro, otorga identidad-pensamiento-maestro en el contexto social, político y cultural.
En este mismo orden de ideas, la escritura del maestro como potencia del pensamiento está marcada por una sinergia entre distintos lugares y tiempos. En primer lugar, el pensamiento maestro hecho palabra: la identidad de los maestros dominada por la configuración de un pensamiento con influjo oral. Desde esta posición el maestro reproduce, es notario y también es creativo, zigzaguero, silencioso y sigiloso en el contexto escolar y sus discursos (Primer lugar y tiempo del maestro). En segundo lugar, la pluralización de la categoría maestro a partir de los 90, esa diversificación del sujeto maestro, el sujeto-estudiante y el lugar-escuela, las otras educaciones, los otros educadores y los otros estudiantes. En fin, modos de ser desvinculados desde el corazón epistémico de la escuela occidental (Segundo lugar y tiempo del maestro). Finalmente, el maestro en red y dialógico. El sujeto-maestro articulado a redes académicas, intelectuales, sociales y políticas que desde la escritura se exponen, se encuentran, se transforma y transforman con otro (Tercer lugar y otro tiempo del maestro).

El encuentro entre los tres lugares y tiempos del maestro, mencionados en el párrafo anterior, y la escritura enriquecerían y transformarían radicalmente la escuela y la academia, puesto que implica pensar la educación, la organización escolar, el currículum, las prácticas pedagógicas, y la escuela desde múltiples orillas; lo cual daría lugar a la globalización de la cultura y el pensamiento humano, nuevo sitio en la escuela donde el maestro tiene un rol fundamental. La escritura como potencia, entonces, se convierte en un nueva posibilidad para la escuela, la academia y producción de un conocimiento amplio, profundo, problemático y divergente que articula en un mismo espacio las disciplinas (trans-diciplinariedad), pero que también encuentre diferentes culturas de conocimiento (la trans-culturalización del conocimiento). El abrazo entre las diferentes orillas a partir de la escritura, configuran una gran potencia en el pensamiento docente y su quehacer pedagógico, por tanto ofrecen un modelo de escuela distinto, dando lugar a unas relaciones radicalmente distintas entre las personas, sujetos escolares y abre posibilidades a nuevas formas de construcción de conocimiento. 
Desde este punto de vista, la escritura se construye como un lugar de alejamiento y extrañamiento, sin embrago, ésta también crea un acercamiento complejo, conjuga lo situacional y lo abstracto, el mundo del lenguaje representado por el espacio y tiempo del evento, la oralidad, y el mundo del lenguaje representado por signos, símbolos, es decir la escritura. La escritura en este contexto desnuda y viste al escritor, construye y de-construye, es observadora y observada, deja de ser alienadora dado que no ofrece feedback y se convierte en dialógica configurando de esta manera una potencia dinámica, contaminante y transformadora que configura en quien escribe, formas distintas ser y estar en el mundo. También, fortalece el encuentro de yo con yo en el otro. Por tanto, humaniza a los seres humanos. La escritura se convierte en otro lugar para transformar las relaciones humanas en la sociedad del conocimiento y en la cultura de la globalización. Pero esta potencia solo es posible en relación con la oralidad. El binomio oralidad-escritura es la potencia realmente hoy en tiempos de globalización.

\section{CONCLUSIÓN}

El lugar de la oralidad no solo obedece a las formas de desarrollo civilizatorio adoptado por un pueblo, sino también a lógicas y a momentos históricos que la originan. Es decir, algunas culturas son situadas en el lugar de la oralidad a razón de estructuras de poder de dominación y de racialización. En la actualidad, algunas comunidades guardan una cercanía con el pensamiento oral, porque históricamente fueron situadas en este lugar. Occidente invalidó las elaboraciones desde la oralidad como supuesto para hacer de su humanidad, sus conocimientos y el pensamiento algo sin trascendencia para la formación de las sociedades y su cultura. Hasta hoy el legado que transita de generación en generación sigue al margen de la escuela y sus epistemologías, aunque exista un amplio marco normativo que lo promueve. Empero, desde otra perspectiva, la oralidad constituye una de las formas de reinvención de las prácticas, pensamientos, cosmovisiones, etc. La oralidad se convirtió en una agencia de re-existencia, libertad y de encuentro con la cultura propia.
En el marco de la producción de conocimiento, no sólo son subvaloradas las comunidades de pensamiento oral, sino también sus intelectuales aún tengan formación en grafía, puesto que históricamente, curiosamente después de 1942 (la tragedia Americana y posteriormente africana), el conocimiento tiene un lugar y una raza: Europa y la "raza blanca”. Según Walsh, (2004a) "la colonialidad del poder instaló una diferencia que no es simplemente étnica y racial, sino también colonial y epistémica, diferencia que ha sido constante en los países de área andina” (p. 335). En este orden de ideas, los conocimientos de las comunidades de pensamiento oral, así como las personas con pertenencia a éstas, alfabetizados, no entran en las escuelas y universidades; ambos son considerados viscerales, primarios, no sesudos, no académicos, no objetivos; aunque la objetividad no exista.

Aunque el tránsito de la oralidad a la escritura reconfigura y transforma la relación comunidad de pensamiento oral, la representación simbólica y de significación, la escritura y la oralidad guardan una relación de interdependencia en la medida en que se dan lugar y soporte de manera recíproca. Es decir, el encuentro entre los documentos o manuscritos y las narraciones orales en el campo de la historiografía recrean un complejo y solido argumento para la reconstrucción de las historias y relatos. De este modo, encontrar la escritura y la oralidad es poner en diálogo dos formas de producción de pensamiento diferenciadas que configuran un binomio que potencia el pensamiento de las personas, dan mayor soporte a la memoria y la identidad individual y colectiva de los pueblos. Además, impulsan el quehacer pedagógico de los etnoeducadores, los nuevos sujetos de la educación, aún más en tiempos donde los saberes y la memoria de las comunidades étnicas viajan por las urbes donde no hay un lugar de dignidad para este saber que se transforma o se esfuma en la inmediatez que imponen las grandes capitales en la lucha por la subsistencia.

La escuela en sus procesos de enseñanza y aprendizaje alberga la produccion de conocimiento que no esta mediada totalmente con la escritura, en contraste, estos procesos se centran en gran 
medida por la oralidad. En el contexto escolar el maestro es reducido a la "escritura notarial", la cual sustenta la marcación de la oralidad en la escuela. En la profesión docente, en la formación basica y media, los docentes enfrentan multiples complejidades sociales que reposan en la escuela y encuentran en ella una posible salida al entramado social: desigualdades sociales, violacion de derechos humanos, derechos laborales, pobrezas sistemáticas e históricas, el capitalismo desenfrenado, sexismo, racismo, etc. En este contexto, las y los maestros viven en la cotidianidad procesos analíticos para la producción de conocimiento como: la contrastación, crítica, comprensión e incorporación, aplicados a los discursos de los textos escolares que leen y las reacciones sociocríticas de las y los estudiantes.

La escritura y la oralidad son técnicas o estrategias independientes a la producción de conocimiento, en tanto que no toda escritura, no toda manifestación de pensamiento oral es per se producción de conocimiento. La producción de conocimiento obedece a procesos complejos de sistematización de formas de aprensión del mundo o de la "realidad". De otra parte, la escritura es una forma o un dispositivo de la ciencia en el mundo moderno; la cual muestra una contradicción en el ámbito escolar entre la demanda por la escritura y el reconocimiento de la diversidad étnica y cultural del país. Éste último supone el reconocimiento de esas otras formas de ser, estar en el mundo. La oralidad, por supuesto, debe ser acogida, en el marco de tal "reconocimiento" por el sistema educativo, las políticas educativas y la escuela sin "folklorizar ni exotizar".

Finalmente, las comunidades deben abrirse a otros dispositivos, multiplicar y democratizar los formatos, que posibiliten salvaguardar la memoria-identidad. La relación escritura y oralidad es problemática porque constituyen formas de pensamiento diferenciados, jerárquicos; aquí pensar la escritura en comunidades de pensamiento oral puede convertirse en una manera de desplazar la cosmovisión de las comunidades y la institución de otro ser de tipo colonial, porque la escritura y la oralidad representan el mundo de manera diferenciada. Sin embargo, se hace necesario encontrar o construir formas o dispositivos alternativos para salvaguardar la memoria-identidad; porque la oralidad-sola, también supone riesgos-posibilidades, en tanto que pude tergiversarse y transformarse, o desaparecer de la memoria-identidad de los pueblos.

\section{REFERENCIAS BIBLIOGRÁFICAS}

Arboleda Q, S. (2011). Le han florecido nuevas estrellas al cielo: suficiencias intimas y clandestinización del pensamiento afrocolombiano. Tesis de Doctorado en Estudios Culturales Latinoamericanos. Universidad Andina Simón Bolivar de Ecuador.

Balerstrini, M. C., \& Chicote, G. (1997). El mester de clerecía en la encrucijada entre oralidad y escritura. Revista de Análisis Semiótico del Discurso, Anclajes. 1, (1), 43-58.

Caicedo O, J. A. (2008). Historia oral como opción política y memoria política como posibilidad histórica para la visibilización étnica por otra escuela. Revista de educación y pedagogía, XX, (52), 27-42. Echeverri J, G. (2005). Escritura-comunicabilidad. En J. C. Echeverri Álvarez, y G. Echeverri Jimenez, Investigar-publicar: una relación hacia la comunicabilidad del conocimiento (p. 93-147). Medellín: Universidad Pontificia Bolivariana.

Echeverri J, G. (2011). la comunicabilidad del conocimiento académico. En Facultad de Educación, Escuela de Educación y Pedagogía, Monográfico Maestría en Educación. (p. 30-39). Medellín: Universidad Pontificia Bolivariana.

Hernández Z, G. (2009). Escritura académica y formación de maestros ipor qué no acaban la tesis? Revista Tiempo de educar.10 (19), 11-40.

Lopera E, J., Ramírez, G. C., Zuluaga, A. M., Ramírez, C. V., Henao, G. C., Carmona, H. D., ... Carmona, O. J., (2007). Relaciones Psicología-Psicoanálisis un estado del arte. Medellín: Universidad de Antioquia.

Mason, B. L. (1998). E-texts: the orality and literacy issue revisited. Oral Tradition, 13, (2), 306-329.

Mina, A. W. (2006). Manuel Zapata Olivella: pensador humanista. Cali: Artes Gráficas del Valle, Ltda.

Munguía A. R. (2010). De la oralidad a la escritura: un acercamiento al conflicto linguístico en los pueblos francófonos del África negra. Revista electrónica de linguística aplicada, (7), 1-10.

Ong, W. (2006). Oralidad y escritura. Tecnologías de la palabra. Buenos Aires: Fondo de Cultura Económica .

Ramos C, G. (2006). Oralidad africana en Cuba: Memoria y discurso de permanencia cultural. Oráfrica , (2), 113-129. 
Suárez R, F. (2010). Etnoeducación: tradición oral y habla en el pacífico colombiano. 200 años de iberoamérica (1810-2010). Congreso Internacional: Actas del XIV encuentro de latinoamericanistas Españoles, Santiago de Compostela, 15-18 de septiembre de 2010). Santiago de Compostela: Universidad de Santiago de Compostela, Servizo de publicacions e intercambio cientifico, (págs. 2508-2534.

Vásquez R, F. (2008). La escritura y su utilidad en la docencia. Actualidades pedagógicas, 101-114.

Vich, V., \& Zavala, V. (2004). oralidad y poder. Herramientas metodológicas. Bogotá D.C: Norma. Walsh, C. (2004a). Colonialidad, conocimiento y diáspora afro-andina: construyendo etnoeducación e interculturalidad en la universidad. En E. Restrepo, \& A. (. Rojas, conflicto e (in) visibilidad. Retos en los estudios de la gente negra en Colombia (págs. 331-346). Popayán: Universidad del Cauca.

Walsh, C. (2004b). Geopolíticas del conocimiento, interculturalidad y descolonización. Boletín ICCI-ARY Rimay, (60), p. 1-5. Ponencia presentada en el evento de la inauguración de la casa de ICCI, "Geopolíticas del Conocimiento y la Descolonización de las Ciencias”, 18 de febrero del 2004.

Zapata, M. J. F. (2010). Oralidad y escritura en la trova Antioqueña. Linguística y literatura, (57), p. 131-145. 